\title{
Design, Fabrication and Performance Evaluation of Hybrid Vertical Axis Wind Turbine
}

\author{
Gwani Mohammed $^{1}$ | Mamuda Buhari ${ }^{1,2}$ | Umar Muhammed Kangiwa ${ }^{1}$ | John Danyaro ${ }^{1}$ \\ 1Department of Physics, Kebbi State University of Science and Technology, Aliero, Kebbi State 1144, Nigeria. \\ 2The Federal Polytechnic, KauraNamoda, Zamfara State, P.M.B 1012, Nigeria. \\ To Cite this Article
}

Gwani Mohammed, Mamuda Buhari, Umar Muhammed Kangiwa and John Danyaro, "Design, Fabrication and Performance Evaluation of Hybrid Vertical Axis Wind Turbine", International Journal for Modern Trends in Science and Technology, Vol. 06, Issue 06, June 2020, pp.:80-86; https://doi.org/10.46501/IJMTST060618

Article Info

Received on 02-May-2020, Revised on 30-May-2020, Accepted on 05-June-2020, Published on 11-June-2020.

\section{ABSTRACT}

Vertical axis wind turbines (VAWT) have attracted a lot of attention recently as an efficient tool in harnessing wind energy; however these types of wind turbine are faced with some challenges which affect their overall performance. The Darrieus rotor has difficulty to self-start by itself while the Savonius rotor has low efficiency. The performance of these turbines can be improved by combining the two VAWTs as one system. This paper presents the design of a hybrid VAWTs turbine. The Hybrid VAWTs combines the Darrieus rotor and the Savonius rotor as a single system to produce a high starting torque and enhanced efficiency. The Savonius rotor is placed at the centre of the three vertical blades of the Darrieus H-rotor to form the hybrid VAWTs. The hybrid VAWT was tested at four different wind speed i.e. $V=4.80 \mathrm{~m} / \mathrm{s}, 4.50 \mathrm{~m} / \mathrm{s}, 4.30 \mathrm{~m} / \mathrm{s}$ and $3.90 \mathrm{~m} / \mathrm{s}$ respectively. The performance of the hybrid VAWT was compared with the conventional straight bladed VAWT under similar experimental conditions. The obtained results showed that there is substantial improvement in the self-starting ability and coefficient of power $\left(C_{p}\right)$. At $V=4.80 \mathrm{~m} / \mathrm{s}$, the $C_{p}$ values for hybrid VAWT increased by $92 \%$ compared to straight bladed H-rotor VAWT. Similar improvement was also observed at wind speed of $V=4.50 \mathrm{~m} / \mathrm{s}, 4.30 \mathrm{~m} / \mathrm{s}$, and $3.90 \mathrm{~m} / \mathrm{s}$ where the $C_{p}$ values increases by $71 \%, 10 \%$, and $67 \%$ respectively compared to the straight bladed H-rotor.

KEYWORDS: H-Darrieus VAWT, wind speed, Hybrid VAWT, Savonius rotor, wind energy

Copyright (C) 2014-2020 International Journal for Modern Trends in Science and Technology

DOI: https://doi.org/10.46501/IJMTST060618

\section{INTRODUCTION}

The major tool for development in any nation is the energy resources; it has forever been a crucial and essential contributor toward achieving the economic obligation of the present-day society. Indeed, it serves as the inspiring strength of industrialization [1]. It is also regarded as an influential parameter of fiscal and societal prospective; there is no country that has developed without ensuring least contact to energy resource beyond a survival economy for a wide section of it populace [2].
The current energy trends and irrational utilization of the world's resources pose a great threat to the globe. Exhaustible reserves of fossil fuels cannot take us to the promise land in terms of economic development, because they are not only improbable, but also harmful to the fragile systems on earth. Imbibing other means of sustainable energy resources to satisfy our increasing energy demand becomes paramount, as scientific researchers have been echoing on eminent environmental tragedy. Renewable energy sources are not only alternative to exhaustible fossil fuel 
reserves, but will go a long way to ameliorate the harm caused by fossil fuel utilization. Presently, a lot of researches are ongoing on the cheapest, reliable and renewable energy sources[3].Different sources of renewable energy include biomass, solar, geothermal, hydroelectric, and wind. Among these resources wind energy has proven to be a cheaper alternative energy resource and hence extensive research efforts have been put to improve the technology of electricity generation through wind [4].

Wind turbines capture the kinetic energy of the air and convert it into rotational mechanical energy and or subsequently into electrical energy [4]. Basically two types of Vertical axis wind turbines are in existence these includes the Darrieus rotor (Egg beater and H-rotor) and the Savonius rotor (Figure 1). Each of these wind turbines has its advantages and disadvantages, the Darrieus rotor is very efficient but has difficulty to self-start by itself while the Savonius rotor can self-start by itself but have low efficiency. The general advantages of the VAWTs includes Suitability for small amount of power generation, it can withstand extreme weather situation, they are lighter in weight, and are easy to maintain and repair compared to the HAWTs and are very suitable for the urban environment [5]. However, the Darrieus turbine has insufficient lift to produce the torque that is capable of overcoming the inertial and drive train confrontation and therefore failing to stimulate the rotation at very low wind speeds. This is considered as one of the disadvantage of the Darrieus rotor[6].

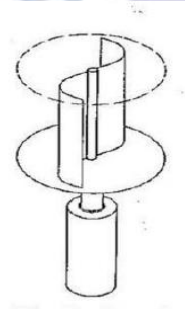

(a)

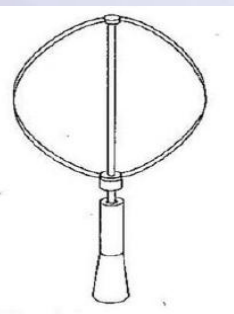

(b)

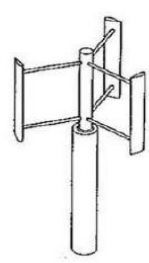

(c)
Figure 1: Type of VAWTs (a)Savonius, (b)Egg-beater, (c) H- rotor [7, 8]

To overcome the predicament of low lift, substantial drag force can be produce to generate the torque even at low wind speed. In this study a hybrid VAWTs is designed, fabricated and tested, the hybrid VAWTs consists of the $\mathrm{H}$ - rotor and Savonius rotor at the centre as a compact system. Savonius rotor excels in operation than the
Darrieus turbine in low wind speed areas. Therefore a hybrid wind turbine will be suitable, but has decrease of power coefficient at high TSR and is inevitable as shown in the previous studies. Many study has be conducted on the hybrid VAWT in order to improve the self-starting capability of the vertical axis wind turbines. DeCosteet al.,[9]designed and constructed a "Self-Starting Darrieus Wind Turbine" with an achievable $C_{p}$ of 0.24 . The turbine's low efficiency was attributed to poor blade profile shape, which was not exact and thus limit the lift generation by the blades. Miauet al.[10] carried out design and testing on straight blades vertical axis wind turbine. Based on the author's findings, "the radial arms are creating a large drag force, which hinders the rotation of the blades. They asserted that by constructing the radial arm inform of an aerodynamic shape in contrast to simply flat plates; can reduce the overall area facing the wind, would significantly lessen the overall drag on the device.

Abu-El-Yaziedet al,.[11] performed a numerical analysis in order to understand the effect of blade number and solidity on the behavior of a straight-bladed vertical-axis wind turbine. It was found that, when the number of blade is lower than 3 , the $\mathrm{C}_{\mathrm{pmax}}$ values increases with increase in solidity, and when the number of blade is more than $3, \mathrm{C}_{\text {pmax }}$ decreased with increase in Solidity and the corresponding tip speed ratio obtained for this maximum power coefficient was decreased with increase in solidity.The Savonius rotor is a design that has high starting torque which is capable of self-starting but its rotational speed and power coefficient is too low. They are normally constructed as a Darrieus with a drag type blade in the middle, as seen in Figure 2. These can normally self-start, but after they have started, they are less efficient than a normal lift type due to the middle creating negative drag [12].

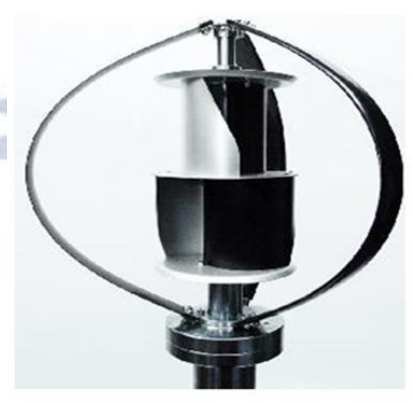

(a)

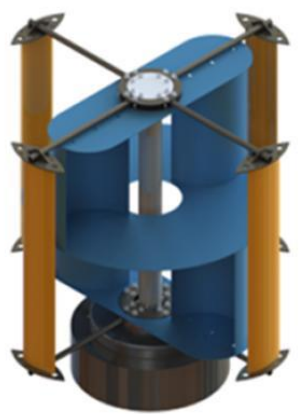

(b)
Figure 2: (a) Egg-beater Hybrid VAWT (b) H-rotor with Savonius in open configuration $[6,12]$. 
Kavade and Pravin[13] experimentally investigate the performance of hybrid turbine for different blades with same aspect ratio the study was done for rotor with two, three, and four blades. The result show that the coefficient of power of three blades rotor is higher than that of the two and four blades at low wind speed. The combination of Savonius and Darrieus rotor (hybrid VAWT) increases the total power of the turbine in low wind speeds and it demonstrate the effectiveness of the hybrid turbine in producing much more power than other commercial turbines Letcher[14].Dwiyantoro, [15] design a hybrid turbine based on a straight bladed Darrieus turbine along with a double step Savonius turbine. The simulated results show that shortening the inner shaft than the structure potency will improve significantly. The hybrid vertical axis wind turbine with the shorter inner shaft have much better self-starting and better conversion efficiency.

Abidet al [16] presents the design, construction and testing of a hybrid vertical axis wind turbine with drag device (Savonius rotor) on the top. The result obtained shows that the turbine with NACA 0030 airfoil (hybrid VAWT) provided the high thickness has resulted in an increase in the self-start capability of the turbine.

\section{Power available in the Wind}

The available power in the wind turbine can be calculated using Equation 1:

$P=\frac{1}{2} p A V^{a}$

Where

$\mathrm{P}$ is power output of a turbine,

$\mathrm{A}$ is area of the rotor blades,

$\mathrm{V}$ is wind speed $(\mathrm{V})$, and

(p) is the density of air $\left(1.23 \mathrm{~kg} / \mathrm{m}^{3}\right)$.

equation (1) indicates the importance of wind speed in power generation. It is noted from equation (1) that the specific power of a wind site is proportional to the cube of the wind speed [17] because power generation increases as wind speed increases to the third power [18]. Betz proved that the maximum kinetic energy that can be extracted from the wind cannot exceed 16/27 (59.3\%). Thus according to this law, no turbine can extract all the power out of the wind streams, and the wind will always have a flow after passing through the turbine [3]. The power coefficient which is the ratio of the available power to the extracted power from the wind turbine can be calculated by rearranging Equation 1.

$$
C_{p}=\frac{p}{0.5 p A V^{3}}
$$

Where

$\mathrm{C}_{\mathrm{p}}$ is the coefficient of power.

\section{Methodology}

\subsection{Design of the Hybrid VAWT}

The Hybrid VAWTs was design using a design software solid work 2016. The parts of straight bladed Darrieus H-rotor and the Savonius rotor was design using this software. Then the rotor support frames (stand) and generator were also design.

\subsection{Design Description of the Hybrid VAWT}

The hybrid VAWTs consist of three main vertical blades and six supporting struts (radial arms) as shown in Figure 3, three of the supporting struts were placed at the top most part of the H-rotor to link the upper part of the vertical blade while the other three supporting struts were used to link the lower part of the vertical blade of the H-rotor to the center shaft. The Savonius rotor was placed at the center of the H-rotor VAWTs between the upper radial arms (supporting struts) and the lower radial arms to form the hybrid VAWT. Both the H-Darrieus VAWT and the Savonius rotor are mounted on the same shaft which is connected to the generator. The vertical blades were fixed at zero degree pitch angle, the complete assemble of the hybrid VAWTs was mounted on a support stand for testing as shown in Figure 3 while the Design parameter is shown in Table 1.

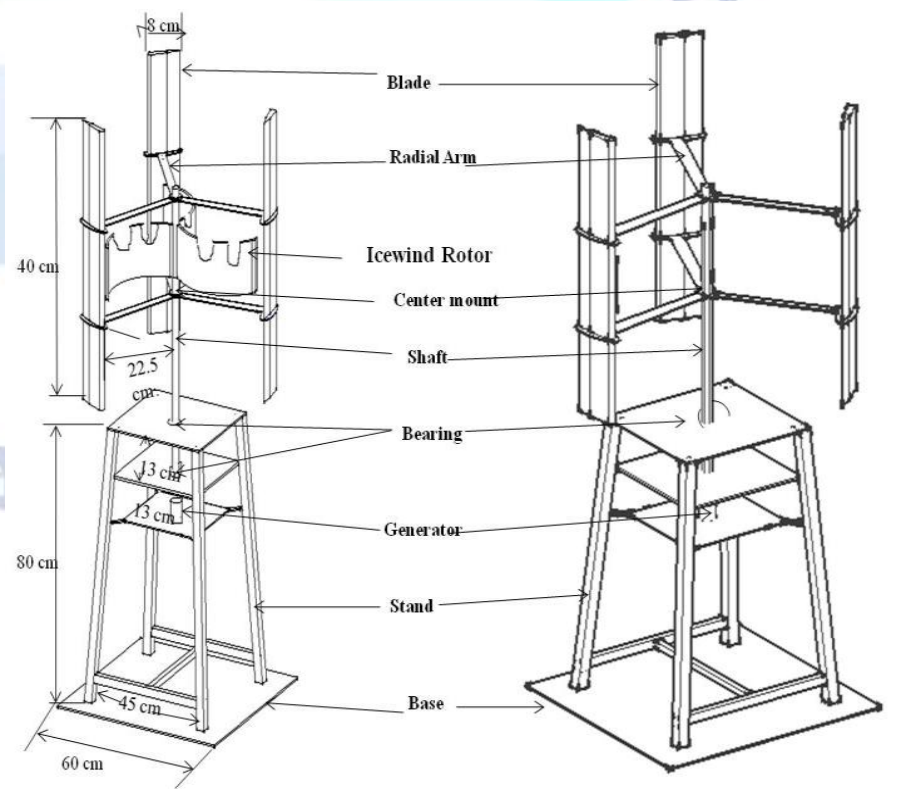

Figure 3: Schematic diagram of the (a) hybrid VAWT (b) H-Darrieus VAWT 
Table 1: Design parameters of the Hybrid VAWT and H-Darrieus VAWT

\begin{tabular}{|c|c|}
\hline Parameter & Value \\
\hline Air foil type & NACA 0012 \\
\hline Drag device type & Savonius rotor \\
\hline Diameter of the turbine (D) & $0.45 \mathrm{~m}$ \\
\hline Radius of the turbine (R) & $0.225 \mathrm{~m}$ \\
\hline Blade height (length) & $0.40 \mathrm{~m}$ \\
\hline Chord length & $0.08 \mathrm{~m}$ \\
\hline Swept Area $\left(A_{s}\right)$ & $0.18 \mathrm{~m}^{2}$ \\
\hline Aspect Ratio & 0.89 \\
\hline Solidity $(\sigma)$ & 0.17 \\
\hline Generator & $10 \mathrm{w}$ \\
\hline Span length (B) & $0.07112 \mathrm{~m}$ \\
\hline
\end{tabular}

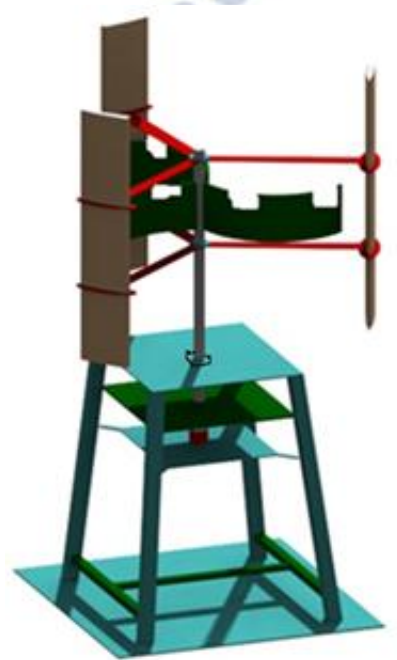

(a)

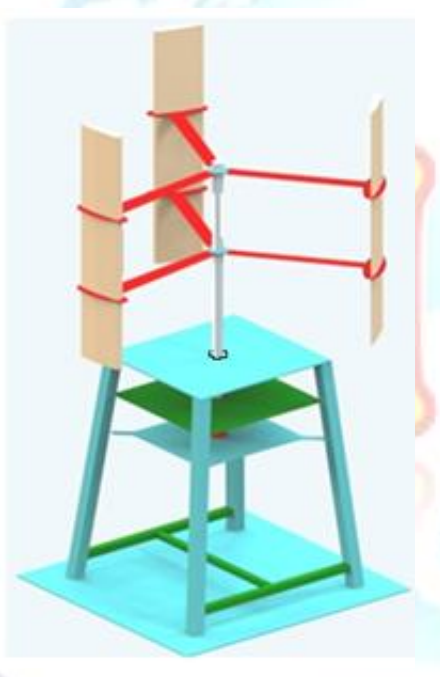

(b)
Figure 4: CAD design of (a) hybrid VAWT (b) $\mathrm{H}$-Darrieus VAWT

\subsection{Experimental Set Up and Procedures}

The experiment was set up at the laboratory of the physics department, Kebbi State University of Science and Technology Aliero. The wind stream used for these experiments was generated using ventilation fans which were placed at a variable distance from the turbine using the set up arrangement of $3 \times 2$ configurations of $100 \mathrm{~cm} \times$ $180 \mathrm{~cm}$ downstream of fans shown in Figure 5. The wind speed was measured using digital anemometer at ten different points for each distance along the direction of the blower, and the average wind speed of $\mathrm{V}=4.80 \mathrm{~m} / \mathrm{s} 4.50 \mathrm{~m} / \mathrm{s}, 4.30$ $\mathrm{m} / \mathrm{s}$, and $3.90 \mathrm{~m} / \mathrm{s}$ respectively was used for the experiments. The rotational speed and RPM was measured using tachometer while the current and voltage was measured using multimeter. Similar procedures were repeated for each wind speed. To evaluate the performance of the hybrid VAWTs similar experimental conditions were employed for the H-Darrieus VAWT for the purpose of comparing the performance of the Hybrid VAWT with the conventional straight bladed VAWT.

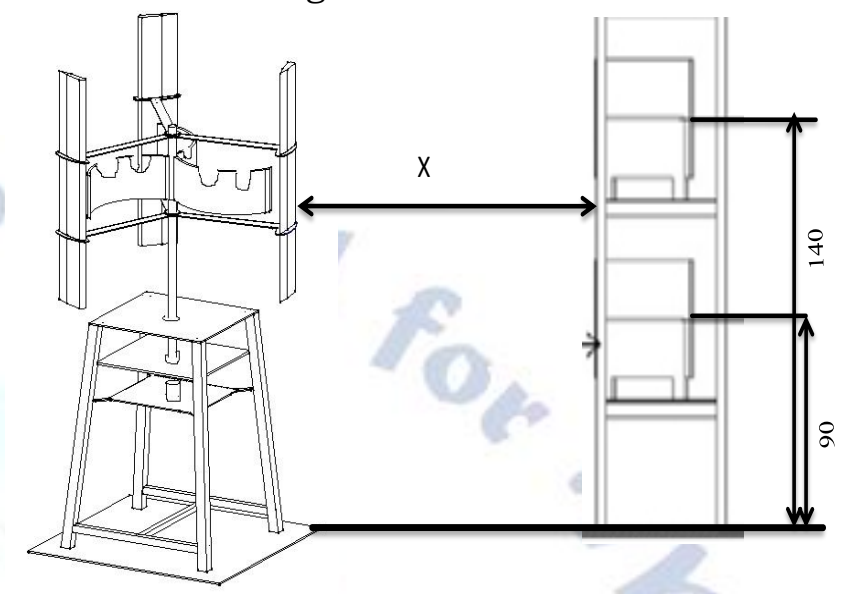

Figure 5: Schematic diagram of the experimental set up (All dimension in $\mathrm{cm}$ )

\subsection{Results}

\section{Results ANd Discussion}

An experiment was performed with H-Darrieus VAWT and Hybrid VAWT at the Physics Laboratory of Kebbi state university of Science and Technology Aliero, Kebbi State. The sets two experiment were performed under same experimental conditions, i.e. one for the hybrid VAWT and another one for H-Darrieus VAWT. The horizontal distance of the two turbines were varied for four different wind speed i.e. $\mathrm{V}=4.80 \mathrm{~m} / \mathrm{s}, 4.50 \mathrm{~m} / \mathrm{s}, 4.30 \mathrm{~m} / \mathrm{s}$ and $3.90 \mathrm{~m} / \mathrm{s}$ respectively. The performance of the Hybrid VAWT and H-Darrieus Turbines were evaluated based on the maximum TSR, RPM and $\mathrm{C}_{\mathrm{p}}$.

\subsubsection{Performance Evaluation of the Hybrid VAWT}

The recording time using stopwatch is started immediately after switching on the ventilation fans. Both turbines were subjected to four different wind speed i.e. $\mathrm{V}=4.80 \mathrm{~m} / \mathrm{s}, 4.50 \mathrm{~m} / \mathrm{s}, 4.30 \mathrm{~m} / \mathrm{s}$, and $3.90 \mathrm{~m} / \mathrm{s}$ respectively. Figure $4.1 \mathrm{a}$ and Figure $4.1 \mathrm{~b}$ shows the rotational speed (RPM) for the hybrid VAWT and that of H-Darrieus VAWT at a wind speed of $\mathrm{v}=4.80 \mathrm{~m} / \mathrm{s}$ and $\mathrm{V}=4.50 \mathrm{~m} / \mathrm{s}$. From the figures, it can be observed that the RPM for both turbines increases steadily with time until maximum RPM values of 505 and 457 was reached at $\mathrm{t}=155 \mathrm{sec}$. and $\mathrm{t}=160 \mathrm{sec}$. respectively for $\mathrm{V}=$ $4.80 \mathrm{~m} / \mathrm{s}$, and a maximum RPM of 454 and 355 at $\mathrm{t}=145 \mathrm{~s}$ and $\mathrm{t}=115 \mathrm{~s}$ respectively, for $\mathrm{V}=4.50 \mathrm{~m} / \mathrm{s}$ 
for both the hybrid VAWT and the straight bladed VAWT. The maximum RPM recorded by the hybrid VAWT is $10.5 \%$ and $27.9 \%$ respectively higher than that of the H-Darrieus VAWT under the similar experimental conditions for both $\mathrm{V}=4.80 \mathrm{~m} / \mathrm{s}$ and $\mathrm{V}=4.50 \mathrm{~m} / \mathrm{s}$ respectively.

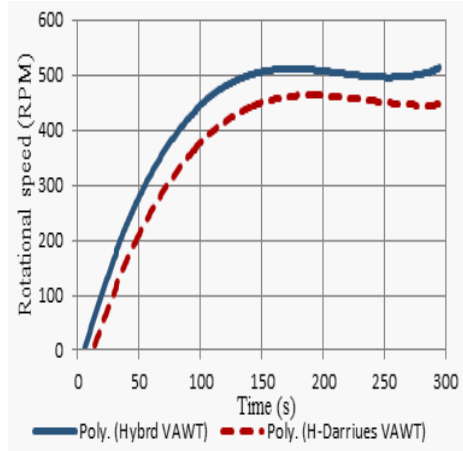

(a)

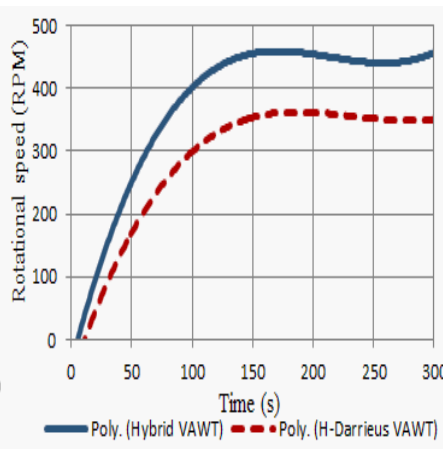

(b)
Figure 4.1: Rotational speed against time for Hybrid and H-Rotor VAWT for (a) V $=4.80 \mathrm{~m} / \mathrm{s}$, (b)

$$
\mathrm{V}=4.50 \mathrm{~m} / \mathrm{s}
$$

Similarly, Figure $4.2 \mathrm{a}$ and $4.2 \mathrm{~b}$, presents the rotation speed per minute (RPM) of the hybrid VAWT and H-Darrieus VAWT for $\mathrm{V}=4.30 \mathrm{~m} / \mathrm{s}$ and $\mathrm{V}=3.90 \mathrm{~m} / \mathrm{s}$. It can be observed from the Figures that the hybrid VAWT outperformed the H-Darrieus VAWT in terms of RPM. The result showed that the RPM of the hybrid VAWT increases by $60 \%$ and $15 \%$, respectively, compared to the H-Darrieus VAWT. The improvement in performance of the hybrid VAWT is as a result of the Savonius rotor couple with H-rotor hence the inability of $\mathrm{H}$ - Darrieus rotor to self-start was eliminated because the coupled Savonius rotor has high starting torque. The results are summarised in Table 2.

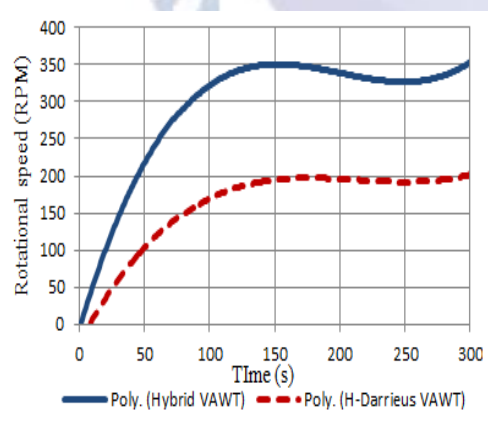

(a)

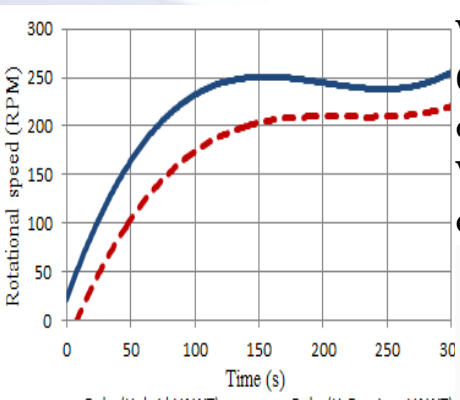

(b)
Figure 4.2: Rotational speed against time for Hybrid and H-Rotor VAWT for (a) V $=4.30 \mathrm{~m} / \mathrm{s}$, (b)

$$
\mathrm{V}=3.90 \mathrm{~m} / \mathrm{s}
$$

Figures 4.3a and 4.3ba compares the Values of $C_{p}$ against the tip speed ratio for the hybrid VAWT and the H-Darrieus VAWT. The results showing similar trend were obtained for Figure 4.3a, V $=4.80 \mathrm{~m} / \mathrm{s}$ and Figure $4.3 \mathrm{~b}, \mathrm{~V}=4.50 \mathrm{~m} / \mathrm{s}$. Based on the result observed in Figure 4.3a, the hybrid VAWT has attained a maximum value of $\mathrm{C}_{\mathrm{p}}$ of 0.023 at a tip speed ratio $(\lambda)$ of 2.12 . The maximum $\mathrm{C}_{\mathrm{p}}$ of the $\mathrm{H}$-Darrieus VAWT is 0.012 at a tip speed ratio $(\lambda)$ of 1.95. The result shows that the maximum $\mathrm{C}_{\mathrm{p}}$ for the hybrid VAWT is $91.67 \%$ higher than the H-Darrieus VAWT. For the case of Figure 4.3b, the maximum $\mathrm{C}_{\mathrm{p}}$ of the hybrid VAWT is 0.031 at a tip speed ratio $(\lambda)$ of 2.16 while the maximum coefficient of power of the H-Darrieus VAWTs is 0.0181 at TSR $(\lambda)$ of 1.71 which indicates that the $\mathrm{C}_{\mathrm{P}}$ values of the hybrid VAWT is $71.3 \%$ higher than that of H-Darrieus VAWT under similar experimental conditions.
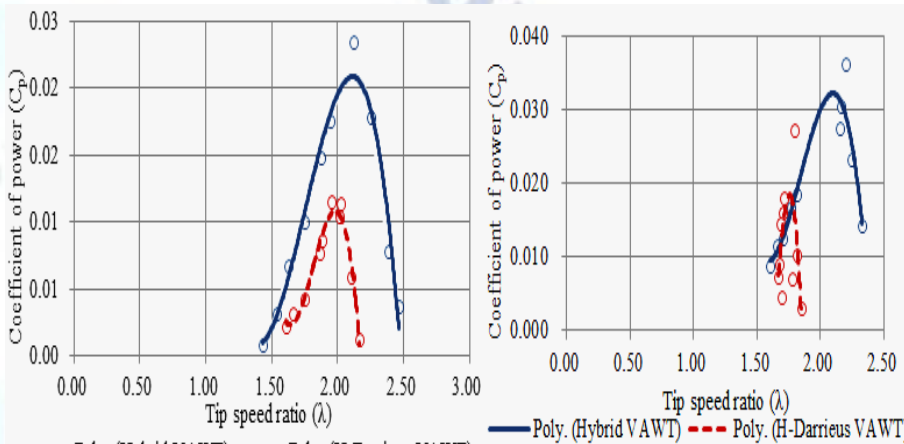

-Poly. (Hybrid VAWT) --- Poly. (H-Darneus VAWT)

Figure 4.3: Coefficient of power against tip speed ratio for Hybrid VAWT and H-Rotor VAWT for (a) $\mathrm{V}=4.80 \mathrm{~m} / \mathrm{s}$, (b) $\mathrm{V}=4.50 \mathrm{~m} / \mathrm{s}$

The $\mathrm{C}_{\mathrm{p}}$ value of the hybrid VAWT and $\mathrm{H}$-Darrieu VAWT for $\mathrm{V}=4,30 \mathrm{~m} / \mathrm{s}$ and $3.90 \mathrm{~m} / \mathrm{s}$ respectively are presented in Figure 4.4 (a) and 4.4 (b). For $\mathrm{V}=$ $4,30 \mathrm{~m} / \mathrm{s}$ it was observe that the hybrid VAWT has high $\mathrm{C}_{\mathrm{p}}$ values than that of H-Darrieus VAWT. The results showed that the maximum $C_{p}$ value attained by the hybrid VAWT and H-Darrieus VAWT are 0.032 at a tip speed ratio $(\lambda)$ of 1.80 and 0.0291 at a TSR $(\lambda)$ of 1.05 respectively. In comparison, the maximum $\mathrm{C}_{\mathrm{p}}$ value for the hybrid VAWT is $9.97 \%$ higher than the maximum $C_{p}$ value of the H-Darrieus VAWT.
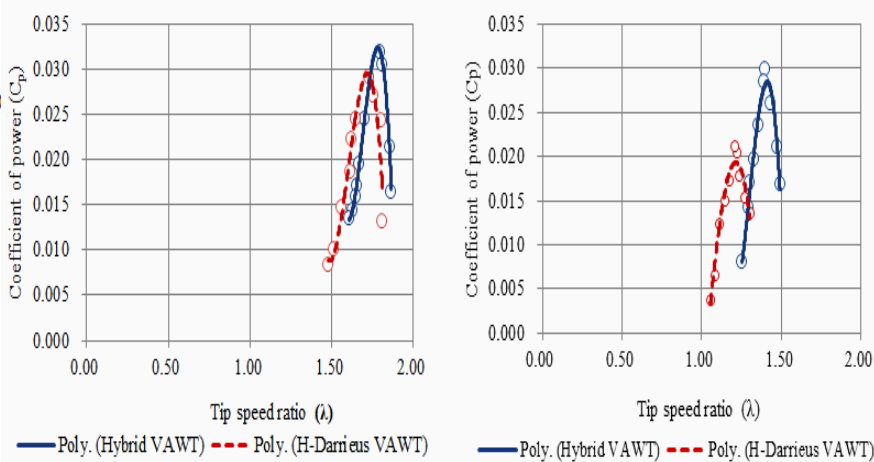

Figure 4.4: Coefficient of power against tip speed ratio for Hybrid VAWT and H-Rotor VAWT for (a) $\mathrm{V}=4.30 \mathrm{~m} / \mathrm{s}$, (b) $\mathrm{V}=3.90 \mathrm{~m} / \mathrm{s}$ 
Similarly, the presented result in Figure $4.4 \mathrm{~b}$ for $\mathrm{v}$ $=4.30 \mathrm{~m} / \mathrm{s}$ indicates that the $\mathrm{C}_{\mathrm{p}}$ value of hybrid VAWT increases by $66.67 \%$ compared to the H-Darrieus VAWT under similar experimental conditions. The maximum $\mathrm{C}_{\mathrm{p}}$ value recorded by the hybrid VAWT and H-Darrieus VAWT are 0.029 at a TSR of 1.39 and 0.0174 at TSR of 1.1 at $\mathrm{V}=3.90$ $\mathrm{m} / \mathrm{s}$. The improved performance of the hybrid VAWT is attributed to the Savonius rotor. The Savonius rotor has a high starting torque which plays an important role in overcoming the self-starting capability of the straight bladed VAWT and improves its overall performance.

Figures $4.5 \mathrm{a}$ and $\mathrm{b}$, compares the coefficient of torque for the hybrid VAWT and that of H-Darrieus VAWT for $\mathrm{V}=4.80$ and $\mathrm{V},=4.50 \mathrm{~m} / \mathrm{s}$. Figure $4.5 \mathrm{a}$ shows the coefficient of torque against the TSR $(\lambda)$ for the hybrid VAWT and H-Darrieus VAWT placed at wind speed of $V=4.80 \mathrm{~m} / \mathrm{s}$. based on the result obtained the hybrid VAWT attain a maximum torque value compared to the H-Darrieus VAWT. The maximum values of coefficient of torque were found to be 0.011 at TSR $(\lambda)$ of 2.12. The maximum coefficient of torque for the H-Darrieus VAWT and subjected to similar experimental conditions is 0.006 at a TSR $(\lambda)$ of 1.95 . The result shows that the maximum coefficient of torque for the hybrid VAWT is $83.3 \%$ higher than that of H-Darrieus VAWT. Figure $4.5 \mathrm{~b}$ compare the coefficient of torque values of the hybrid VAWT and that of the H- Darrieus VAWT at wind speed of V $=4.50 \mathrm{~m} / \mathrm{s}$, from the figure it can be observed that that the hybrid VAWT has outperformed the H-Darrieus VAWT The maximum coefficient of torque of the hybrid VAWT is 0.017 at a TSR $(\lambda)$ of 2.20 which is $183.3 \%$ higher than that of H-Darrieus VAWT whose maximum coefficient of torque is 0.006 at TSR $(\lambda)$ of 1.79 .
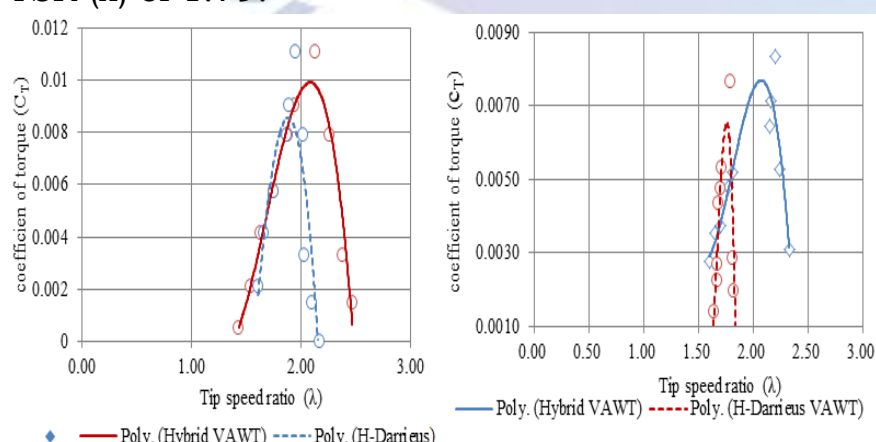

Figure 4.5: Coefficient of Torque against tip speed ratio for Hybrid VAWT and H-Rotor VAWT for

(a) $\mathrm{V}=4.80 \mathrm{~m} / \mathrm{s}$, (b) $\mathrm{V}=4.50 \mathrm{~m} / \mathrm{s}$

Figure $4.6 \mathrm{a}$ and $\mathrm{b}$ presents the coefficient of torque value of the hybrid VAWT and H-Darrieus VAWT for $\mathrm{V}=4.30 \mathrm{~m} / \mathrm{s}$ and $3.90 \mathrm{~m} / \mathrm{s}$ respectively. It was observe that hybrid VAWT has high coefficient of torque than that of H-Darrieus VAWT. The results showed that the maximum coefficient of torque value attained by the hybrid VAWT and $\mathrm{H}$-Darrieus VAWT are 0.018 at a TSR $(\lambda)$ of 1.80 and 0.017 at a TSR ( $\lambda$ ) of 1.73 respectively. In comparison, the maximum coefficient of torque value for the hybrid VAWT is $5.88 \%$ higher than that of the H-Darrieus VAWT. Similarly, the presented result in Figure $4.6 \mathrm{~b}$ for $\mathrm{V}=3.90 \mathrm{~m} / \mathrm{s}$ shows that the maximum coefficient of torque obtained by the hybrid VAWT and H-Darrieus VAWT are 0.021 at a TSR $(\lambda)$ of 1.40 and 0.017 at a TSR $(\lambda)$ of 1.22 , this indicates that the coefficient of torque for the hybrid VAWT increases by $23.53 \%$ compared to the H-Darrieus VAWT under similar experimental conditions. The improved performance of the hybrid VAWT is attributed to the high starting torque of the Savonius rotor, which enable the hybrid VAWT to self-start earlier. The Savonius rotor contributes significantly to the self-starting ability of the VAWT which eventually reduce the cut-in speed, thus extending the operating range of the rotor and increasing the energy harvesting ability of the hybrid VAWT. The results is summarised in Table 2 .
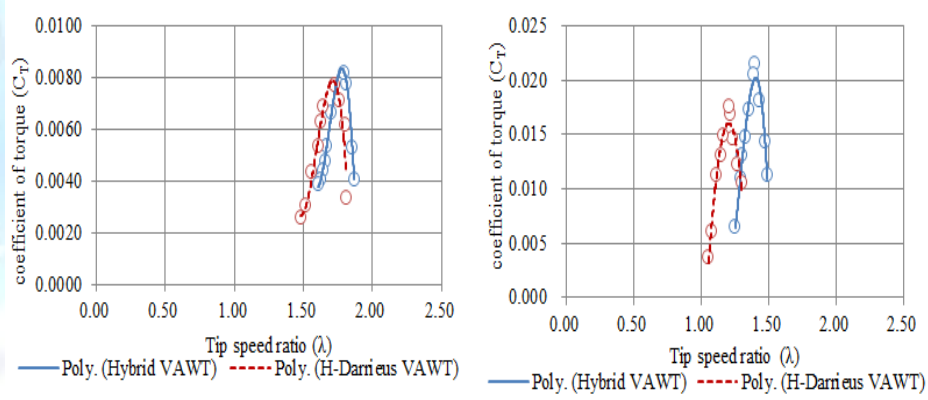

Figure 4.6: Coefficient of Torque against tip speed ratio for Hybrid VAWT and H-Rotor VAWT for (a) V $=4.30 \mathrm{~m} / \mathrm{s}$, (b) $\mathrm{V}=3.90 \mathrm{~m} / \mathrm{s}$

Table 2: Summary of the result for hybrid VAWT and H-Darrieus VAWT at maximum values

\begin{tabular}{lllll}
\hline $\begin{array}{l}\text { Wind Spe } \\
\text { ed }(\mathrm{m} / \mathrm{s})\end{array}$ & $\begin{array}{l}\text { Param } \\
\text { eters }\end{array}$ & $\begin{array}{l}\text { Hybrid } \\
\text { VAWT }\end{array}$ & $\begin{array}{l}\text { H-Darrie } \\
\text { us VAWT }\end{array}$ & $\begin{array}{l}\text { Percenta } \\
\text { ge } \\
\text { Increase }\end{array}$ \\
\hline \multirow{4}{*}{4.80} & RPM & 505 & 457 & 10.5 \\
& $\mathrm{C}_{\text {p. Max. }}$ & 0.023 & 0.012 & 92 \\
& TSR & 2.12 & 1.95 & 87 \\
& $\mathrm{C}_{\text {t. Max. }}$ & 0.011 & 0.006 & 83 \\
\hline \multirow{4}{*}{4.50} & RPM & 454 & 355 & 27.9 \\
& $\mathrm{C}_{\text {pMax. }}$ & 0.031 & 0.0181 & 72 \\
& TSR & 2.16 & 1.71 & 26 \\
& $\mathrm{C}_{\text {tMax. }}$ & 0.017 & 0.006 & 2 \\
\hline \multirow{3}{*}{4.30} & RPM & 341 & 214 & 60 \\
& $\mathrm{C}_{\text {p. .Max. }}$ & 0.032 & 0.0291 & 100
\end{tabular}




\begin{tabular}{lllll} 
& & & & \\
& TSR & 1.8 & 1.05 & 71 \\
& Ct & 0.018 & 0.017 & 6 \\
& Max. & & & \\
\hline \multirow{3}{*}{3.90} & RPM & 245 & 213 & 15 \\
& C & & \\
& TS. Max. & 0.029 & 0.0174 & 67 \\
& TSR & 1.39 & 1.17 & 19 \\
& C. Max. $_{\text {t. }}$ & 0.021 & 0.017 & 24 \\
\hline
\end{tabular}

Renewable \& Sustainable Energy Reviews, vol. 16, pp. 1926-1939.

[5] Saha, U.K. and Rajkumar, M.J., (2006) "On the performance analysis of Savonius rotor with twisted blades," Renewable Energy, vol. 31, pp. 1776-1788.

[6] Kumar, M.P., Anbazhagan, S., Srikanth, N., and Lim, T., (2017) "Optimization, Design, and Construction of Field Test Prototypes of Adaptive Hybrid Darrieus Turbine " Journal of Fundamentals of Renewable Energy and Applications, vol. 7, pp. 1-9.

The case is not the same for the H-Darrieus VAWT. The low $\mathrm{C}_{\mathrm{p}}$ output of the H-Darrieus VAWT is attributed to difficulty of the H-Darrieus rotor to self-start by itself which has prolonged the cut-in wind speed. The poor self-starting ability of the $\mathrm{H}$-Darrieus rotor is attributed to the supporting struts of the H-rotor which inevitably affect the power output of the turbine due to the additional drag produce by the supporting struts during rotation thereby reducing the overall performance of the H-Darrieus VAWT.

\section{Conclusions}

In this paper Hybrid VAWT has been designed, fabricated and tested in an experiment. The results obtained from the study showed that the coefficient of power, $\mathrm{C}_{\mathrm{p}}$ of the hybrid VAWT improved momentously compared to the H-Darrieus VAWT. At $\mathrm{V}=4.80 \mathrm{~m} / \mathrm{s}$, the maximum value of $\mathrm{C}_{\mathrm{p}}$, for the hybrid VAWT has increased by $91.67 \%$ at a tip speed ratio $(\lambda)$ of 2.12 compared to the H-Darrieus VAWT under the similar experimental conditions. Similar improvement in performance of hybrid VAWT is also observed for all conditions of wind speed, i.e., $\mathrm{V}=4.50 \mathrm{~m} / \mathrm{s}, 4.30 \mathrm{~m} / \mathrm{s}$, and $3.90 \mathrm{~m} / \mathrm{s}$ respectively where the coefficient of power of the hybrid VAWT outperformed that of the conventional H-Darrieus rotor.

\section{Acknowledgement}

The author will like to thank the Kebbi State University for providing the funding and the enabling environment to carry out the research.

\section{REFERENCES}

[1] Sambo, A.S., (2005) "Renewable Energy for Rural Development:The Nigerian Perspective.," ISESCO Science and Technology Vision, vol. 1, pp. 12-22.

[2] Newsom, C., (2012) "Renewable Energy Potential in Nigeria: Low-carbon approaches to tackling Nigeria's energy poverty," International Institute for Environment and Development, pp. 1-36.

[3] Darhmaoui, H. and Sheikh, N., (2017) "Savonius Vertical Wind Turbine: Design, and Simulation " Thesis Al Akhawayn University.

[4] Aslam Bhutta, M.M., Nasir Hayat, A.U., Zain Ali, F., Rehan, J.S., and Zahid, H., (2012) "Vertical axis wind turbine - A review of various configurations and design techniques,"

86 International Journal for Modern Trends in Science and Technology 